\title{
Therapeutic alternatives in painful diabetic neuropathy: a meta-analysis of randomized controlled trials
}

${ }^{1}$ Pain Clinic, University Hospital Virgen del Rocío, ${ }^{2}$ Department of Nursing, Physiotherapy and Podiatry, University of Seville, ${ }^{3}$ Department of Nursing, Physiotherapy and Podiatry, University Hospital Cruz Roja, Seville, Spain

\author{
Samuel Vilar ${ }^{1}$, Jose Manuel Castillo², Pedro V. Munuera Martínez ${ }^{2}$, María Reina ${ }^{2}$, and Manuel Pabón ${ }^{3}$
}

Background: One of the most frequent problems caused by diabetes is the so called painful diabetic neuropathy. This condition can be treated through numerous types of therapy. The purpose of this study was to analyze, as a meta-analysis, different treatments used to alleviate painful diabetic neuropathy, with the aim of generating results that help making decisions when applying such treatments to tackle this pathology.

Methods: A search was conducted in the main databases for Health Sciences, such as PUBMED, Web of Science (WOS), and IME biomedicina (Spanish Medical Reports in Biomedicine), to gather randomized controlled trials about treatments used for painful diabetic neuropathy. The analyzed studies were required to meet the inclusion criteria selected, especially those results related to pain intensity.

Results: Nine randomized controlled trials were chosen. The meta-analysis shows significant positive effects for those treatments based on tapentadol [g: -1.333 , 95\% CI $(-1.594 ;-1.072), P<0.05$ ], duloxetine [g: $-1.622,95 \%$ CI $(-1.650 ;-1.594), P<0.05]$, pregabalin [g: -0.607 , 95\% CI $(-0.980 ;-0.325), P<0.05$ ], and clonidine [g: $-0.242,95 \%$ CI $(-0.543 ;-0.058), P<0.05]$

Conclusions: This meta-analysis indicates the effectiveness of the treatments based on duloxetine, gabapentin and pregabalin, as well as other drugs, such as tapentadol and topic clonidine, whose use is better prescribed in more specific situations. The results provided can help increase the knowledge about the treatment of painful diabetic neuropathy and also in the making of clinical practice guidelines for healthcare professionals. (Korean J Pain 2018; 31: 253-60)

Key Words: Chronic pain; Diabetes complications; Diabetic neuropathies; Pain; Pain management; Pain unit.

\section{INTRODUCTION}

Diabetes is one of the most important and prevalent diseases in current society, with approximately 415 million people affected worldwide in 2015 and an estimate for the year 2040 of 642 million people [1]. Given the importance of this detail, one of the consequences of this disease must be highlighted, which is the diabetic foot, defined by the

Received March 30, 2018. Revised June 22, 2018. Accepted June 22, 2018.

Correspondence to: Samuel Vilar

Pain Clinic, University Hospital Virgen del Rocío, C/Juventudes Musicales 13, Blq. 9, 13, 2º , Seville 41015, Spain

Tel: +34-627059599, E-mail: samuelvilarpalomo@hotmail.com

() This is an open-access article distributed under the terms of the Creative Commons Attribution Non-Commercial License (http:// creativecommons.org/licenses/by-nc/4.0/), which permits unrestricted non-commercial use, distribution, and reproduction in any medium, provided the original work is properly cited.

Copyright (C) The Korean Pain Society, 2018 
WHO (World Health Organization) as "the presence of ulceration, infection and/or gangrene in the foot associated with diabetic neuropathy and different degrees of peripheral vascular disease as a consequence of the complex interaction of different factors induced by maintained hyperglycemia" [2].

One of the most frequent problems among the patients who suffer from this condition is neuropathic pain, which in scientific terminology is known as painful diabetic neuropathy. It was defined by Boulton et al. (2005) [3] as the "presence of symptoms and/or signs of peripheral nervous dysfunction in people with diabetes, after excluding other causes".

Painful diabetic neuropathy is treated through numerous therapeutic alternatives. The most common therapies are based on antidepressants, anticonvulsants, antipsychotics, opioids, local anesthetics and inhibitors of serotonin and noradrenaline reuptake, among others. In addition to these drugs, most of which are administered orally, there are other ways of application, also commonly used, such as patches or creams, as well as non-pharmacological treatments, as is the case of physical therapies [4-8].

All of the abovementioned motivated the realization of the present study, which analyzed, as a meta-analysis, different treatments used to alleviate painful diabetic neuropathy, with the aim of generating results that help making decisions when applying such treatments to tackle this pathology.

\section{MATERIALS AND METHODS}

This meta-analysis was conducted following the "Preferred Reporting Items for Systematic Reviews and Meta-analysis (PRISMA)" guidelines [9].

\section{Data sources}

To obtain the data, a search in the main databases for Health Sciences, such as PUBMED, Web of Science (WOS) and IME biomedicina (Spanish Medical Reports in Biomedicine) was conducted, using the combination of the terms "pain", "painful diabetic neuropathy", "diabetic neuropathy", "neuropathic pain", "treatment”, "therapy", “dolor neuropático", "dolor", "neuropatía diabética”, "neuropatía diabética dolorosa", "tratamiento" and "terapia" through the boolean operators AND and OR, and the use of truncations.

Example of full electronic search strategy for a database

PUBMED: "Painful diabetic neuropathy" AND (treatment OR therap*)

All the resulting articles, regardless of their publication date, were susceptible of inclusion in the study, until the final date of the search.

\section{Selection of studies}

All those randomized controlled trials that were accessible in full-text and met the inclusion criteria according to the PICO process (P: patient; I: intervention; C: comparison; $\mathrm{O}$ : outcomes) were included.

1. Patients: Patients over 18 years of age, diabetic, and with neuropathic pain.

2. Intervention: Application of physical, topical or oral therapy for the treatment of painful diabetic neuropathy.

3. Comparison: Randomized clinical trials compared with a control group.

4. Outcomes: Measuring of the initial and final pain according to the corresponding scale.

The authors excluded those articles that lacked the pain assessment scale, the demographic characteristics of the sample and the data of the statistical analyses performed that would be necessary for the later realization of the meta-analysis.

\section{Data extraction}

Surveys were carried out to collect the data of the potentially eligible studies. They gathered the data about the sample size, the type of intervention performed and dosage, the comparison conducted, the results obtained related to the measurement of initial and final pain (with standard deviation), the pain scale used, the duration of the diabetes, the duration of the neuropathic pain, the follow up time of the patients and reference. This extraction was performed by the main author of the present study and an external collaborator. In the absence of indispensable data for the realization of the meta-analysis, the authors of those studies involved were contacted and asked for this information. In all the cases in which the authors were contacted (via e-mail), there was either no reply or 
the $\mathrm{e}$-mail address provided in the article did no longer exist.

\section{Measures of quality and risk of bias for the studies}

As a quality measure, the Jadad scale was used. This scale described by Jadad et al. (1996) [10] is an instrument that measures the methodological quality of randomized trials in pain research, thus the authors of the present study consider it essential to apply it in the studies selected. The scale was applied to these articles, excluding those that did not obtain a score of 3 or higher.

As a risk of bias assessment, the articles that were not excluded were screened using the tool provided by the Cochrane Collaboration. This tool is based on domains like random sequence generation, allocation concealment, blinding of participants and personnel, blinding of outcome assessment, incomplete outcome data, selective reporting, and other bias. According to these domains, each study can be classified as high risk, low risk and unclear risk $[11,12]$.

Both the Jadad scale and the Cochrane Collaboration tool for risk of bias assessment were applied in parallel by the main author and an external collaborator. Similar results were obtained from both researchers.

\section{Statistical analysis}

For the analysis and interpretation of the data of the studies selected, the mean value of the final pain and the effect size of each of the studies were calculated, as measurements of central tendency and dispersion. The standard deviation is the statistical element that takes into account both components, which allows to properly weight each study included in the meta-analysis; therefore, it was considered as inclusion criterion that each study had the mean value and the standard deviation for final pain both in the experimental group and in the placebo group.

The effect size was calculated for each of the articles selected, as well as the global effect size for each of the treatment types. Hedge's $g$ is a standardized measurement of the effect size that allows to compare assessments performed with different tests and scales. This measurement of the effect size does not indicate how many standard deviations the effect has. The interpretation of this measure is based on the $\mathrm{g}$ value in absolute value, specifically:
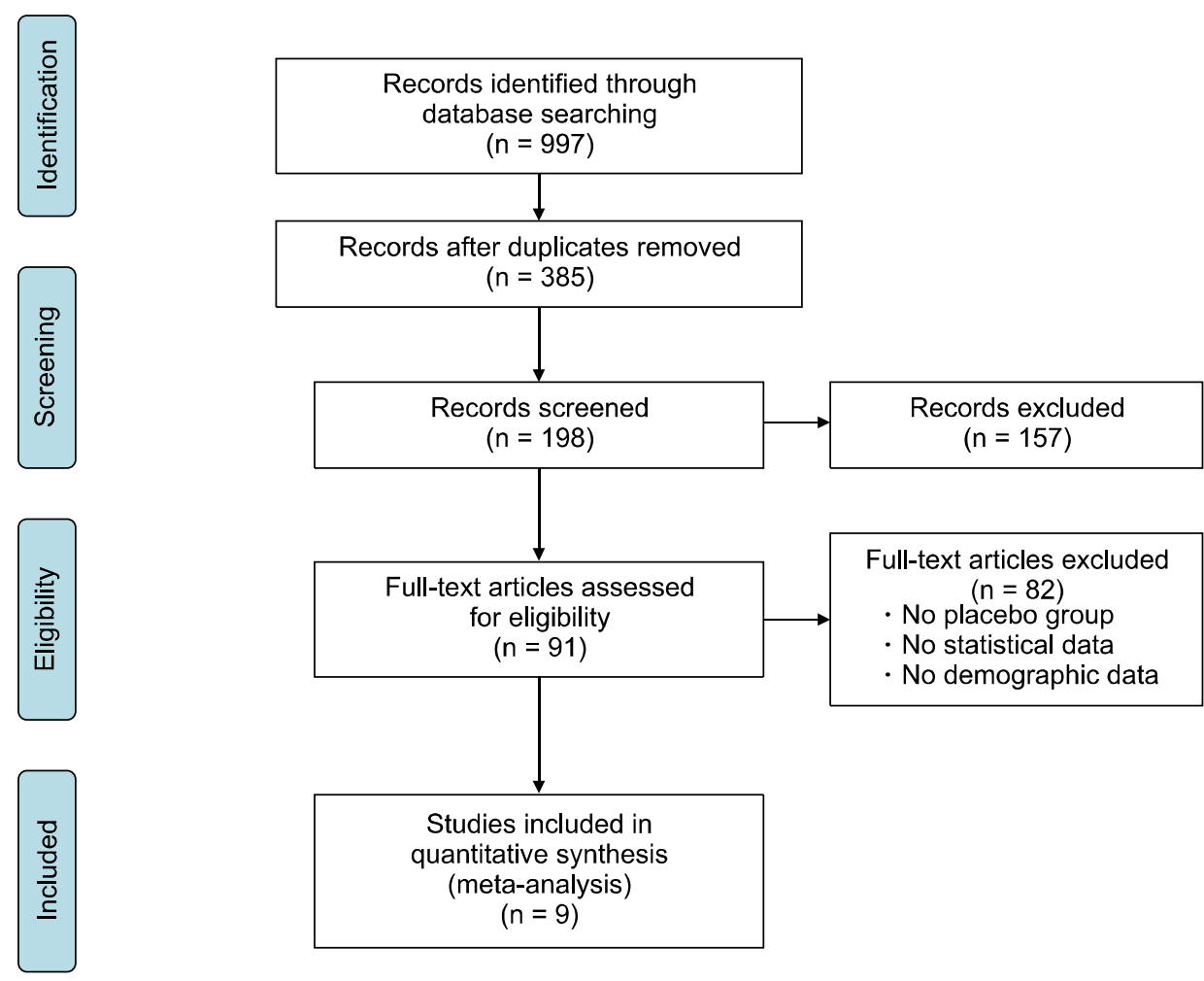

Fig. 1. Flow diagram of the included studies. 
1. absolute g value $0-0.2$ : no effect

2. absolute $g$ value $0.2-0.5$ : small effect

3. absolute $g$ value 0.5-0.8: medium effect

4. absolute $\mathrm{g}$ value $>0.8$ : large effect

A forest plot was used for the graphical representation of the confidence intervals of the values of the effect size. It was interpreted in a way that negative values indicate pain improvement. All those confidence intervals that included zero were not considered significant in the improvement of pain.

\section{RESULTS}

\section{Search results}

From the initial search in the different databases, 997 ar- ticles were obtained for analysis, of which 9 were eventually included after applying the inclusion criteria and analyzing them in detail (Fig. 1).

These 9 articles include topical therapies (clonidine and capsaicin), physical therapies through two types of magnetotherapy, and oral pharmacological therapies such as gabapentin, pregabalin, duloxetine, topiramate and tapentadol. The characteristics of the studies are shown in Table 1 [13-21].

\section{Risk of bias and quality measures}

Of the articles analyzed using the Cochrane Collaboration tool, "low risk" was obtained in a large percentage of them, with two studies showing this in all their domains. In two other articles there was "high risk" in the domain

Table 1. Characteristics of the Studies Analyzed

\begin{tabular}{|c|c|c|c|c|c|c|c|}
\hline Author & Origin & Kind of treatment & Dose or applied therapy & $\mathrm{N}$ total & Men & Women & $\begin{array}{l}\text { Jadad } \\
\text { scale }\end{array}$ \\
\hline $\begin{array}{l}\text { Goldstein et al., } \\
2005 \text { [13] }\end{array}$ & USA & $\begin{array}{l}\text { Oral medicines } \\
\text { (duloxetine) }\end{array}$ & $\begin{array}{l}20 \mathrm{mg} / \text { day } \\
60 \mathrm{mg} / \text { day } \\
120 \mathrm{mg} / \text { day }\end{array}$ & 457 & 281 & 176 & 5 \\
\hline $\begin{array}{l}\text { Niesters et al., } \\
2014 \text { [14] }\end{array}$ & $\begin{array}{l}\text { The Netherlands } \\
\text { and Denmark }\end{array}$ & $\begin{array}{l}\text { Oral medicines } \\
\text { (tapentadol) }\end{array}$ & $500 \mathrm{mg} /$ day & 24 & 14 & 10 & 5 \\
\hline $\begin{array}{l}\text { Richter et al., } \\
2005 \text { [15] }\end{array}$ & USA & $\begin{array}{l}\text { Oral medicines } \\
\text { (pregabalin) }\end{array}$ & $\begin{array}{l}150 \mathrm{mg} / \text { day } \\
600 \mathrm{mg} / \text { day }\end{array}$ & 246 & 149 & 97 & 5 \\
\hline $\begin{array}{l}\text { Campbell et al., } \\
2012 \text { [16] }\end{array}$ & USA & $\begin{array}{l}\text { Topical therapies } \\
\text { (clonidine) }\end{array}$ & $3.9 \mathrm{mg} /$ day & 179 & 86 & 93 & 5 \\
\hline $\begin{array}{l}\text { Rauck et al., } \\
2013 \text { [17] }\end{array}$ & USA & $\begin{array}{l}\text { Oral medicines } \\
\text { (gabapentin and } \\
\text { pregabalin) }\end{array}$ & $\begin{array}{l}\text { GAB } 1200 \mathrm{mg} / \text { day } \\
\text { GAB } 2400 \mathrm{mg} / \text { day } \\
\text { GAB } 3600 \mathrm{mg} / \text { day } \\
\text { PRE } 300 \mathrm{mg} / \text { day }\end{array}$ & 420 & 249 & 171 & 5 \\
\hline $\begin{array}{l}\text { Weintraub et al., } \\
2009 \text { [18] }\end{array}$ & USA & $\begin{array}{l}\text { Pulsed } \\
\text { Electromagnetic } \\
\text { Fields }\end{array}$ & $\begin{array}{l}\text { Divided sessions of } 10 \text { to } 30 \\
\text { minutes (max. } 2 \text { hours a } \\
\text { day) on the feet for } 3 \\
\text { months }\end{array}$ & 194 & $\begin{array}{c}43.3 \% \\
\text { of the } \\
\text { PEMF } \\
\text { group } \\
44.2 \% \\
\text { of the } \\
\text { sham } \\
\text { group }\end{array}$ & $\begin{array}{l}56.7 \% \\
\text { of the } \\
\text { PEMF } \\
\text { group } \\
55.8 \% \\
\text { of the } \\
\text { sham } \\
\text { group }\end{array}$ & 5 \\
\hline $\begin{array}{l}\text { Weintraub et al., } \\
2003 \text { [19] }\end{array}$ & USA & Static Magnetic Field & $\begin{array}{l}\text { Subjects wear constantly } \\
\text { magnetized insoles for } 4 \\
\text { month }\end{array}$ & 259 & 135 & 124 & 5 \\
\hline $\begin{array}{l}\text { Donofrio et al., } \\
2005 \text { [20] }\end{array}$ & USA & $\begin{array}{l}\text { Oral medicines } \\
\text { (topiramate) }\end{array}$ & $600 \mathrm{mg} /$ day & 203 & 106 & 97 & 4 \\
\hline $\begin{array}{l}\text { Kulkantrakorn et al., } \\
2013 \text { [21] }\end{array}$ & Thailand & $\begin{array}{l}\text { Topical therapies } \\
\text { (capsaicin } 0.025 \% \text { ) }\end{array}$ & $\begin{array}{l}2 \text { inches of gel topically, 3-4 } \\
\text { times a day. }\end{array}$ & 33 & 16 & 17 & 5 \\
\hline
\end{tabular}

GAB: Gabapentin, PRE: Pregabalin, PEMF: Pulsed Electromagnetic Fields. 
"Blinding of participants and personnel" due to the lack of blinding throughout the study, since it does not mention whether or not it was performed (Fig. 2, 3).

With respect to the Jadad scale for the measurement of the methodological quality of randomized clinical trials, values over 3 points were obtained in all the articles analyzed, as can be seen in Table 1.

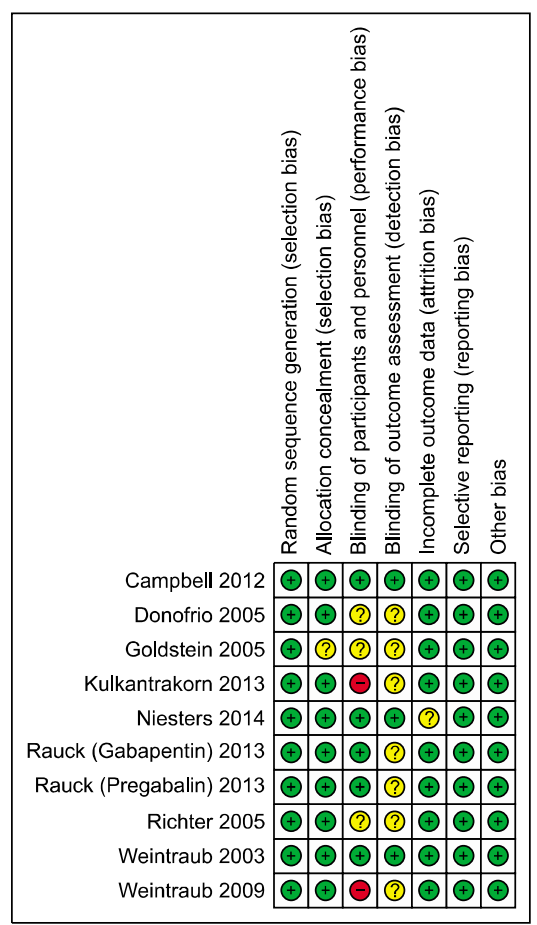

Fig. 2. Risk of bias summary.

Random sequence generation (selection bias) Allocation concealment (selection bias) Blinding of participants and personnel (performance bias) Blinding of outcome assessement (detection bias) Incomplete outcome data (attrition bias) Selective reporting (reporting bias) Other bias

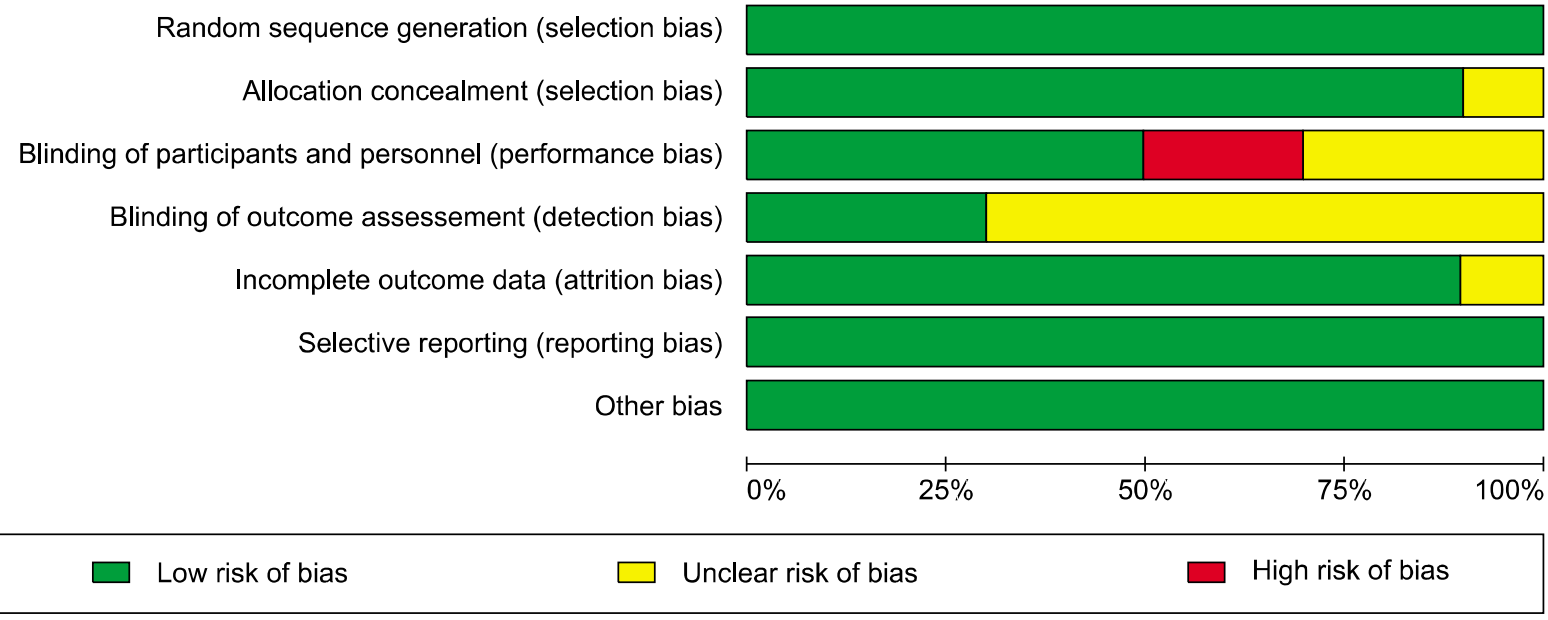

\section{Meta-analytical results}

Regarding the types of therapy included in the meta-analysis, two therapies showed no effect, which were the physical therapy [g: $-0.052,95 \% \mathrm{CI}(-0.229 ; 0.194)]$ and the topical therapy [g: $-0.238,95 \%$ CI $(-0.524 ; 0.047)]$. The oral therapy obtained a small effect size $[\mathrm{g}:-0.266,95 \%$ CI $(-0.357 ;-0.175)]$.

With respect to the individual results of the studies analyzed about the level of final pain, there were two studies with a large effect size, wich are Goldstein et al. [13] about duloxetine at $20 \mathrm{mg} /$ day [g: $-1.622,95 \%$ CI (1.650; -1.594), $P<0.05$ ] and Niesters et al. [14] about tapentadol [g: -1.333 , 95\% CI $(-1.594 ;-1.072), P<$ 0.05]. The study by Richter et al. [15] about pregabalin at $600 \mathrm{mg} /$ day [g: $-0.607,95 \%$ CI $(-0.980 ;-0.325), P<$ 0.05] showed a medium effect size. The studies with a small effect size were those by Richter et al. [15] about pregabalin at $150 \mathrm{mg} /$ day (g: $-0.407,95 \%$ CI [-0.744; $-0.070] P<0.05]$ and Campbell et al. [16] about clonidine [g: $-0.242,95 \% \mathrm{Cl}(-0.543 ;-0.058), P<0.05]$ (Fig. 4).

\section{DISCUSSION}

The main purpose of this meta-analysis was to determine the level of effectiveness of the treatments included in nine clinical trials analyzed. The results obtained through this study indicate that the clinical trials by Richter et al. [15], Niesters et al. [14], Campbell et al. [16], and Goldstein et al. [13] (in the latter case the dose analyzed was 20
Low risk of bias Unclear risk of bias

Fig. 3. Risk of bias graph. 


\begin{tabular}{|c|c|c|c|c|}
\hline Study name & Hedges g & Lower limit & Upper limit & $P$-value \\
\hline $\begin{array}{c}\text { Pulsed electromagnetic } \\
\text { field } \\
\text { Weintraub et al., } 2009\end{array}$ & -0.031 & -0.394 & 0.333 & $P>0.05$ \\
\hline $\begin{array}{l}\begin{array}{c}\text { Static electromagnetic } \\
\text { field }\end{array} \\
\text { Weintraub et al., } 2003\end{array}$ & -0.073 & -0.407 & 0.262 & $P>0.05$ \\
\hline Physical therapies & -0.052 & -0.229 & 0.194 & $P>0.05$ \\
\hline $\begin{array}{l}\text { Gabapentin } 1,200 \mathrm{mg} / \text { day } \\
\text { Rauck et al., } 2013\end{array}$ & -0.138 & -0.463 & 0.187 & $P>0.05$ \\
\hline $\begin{array}{l}\text { Gabapentin } 2,400 \mathrm{mg} / \mathrm{day} \\
\text { Rauck et al., } 2013\end{array}$ & -0.019 & -0.324 & 0.285 & $P>0.05$ \\
\hline $\begin{array}{c}\text { Gabapentin 3,600 mg/day } \\
\text { Rauck et al., } 2013\end{array}$ & -0.204 & -0.491 & 0.083 & $P>0.05$ \\
\hline $\begin{array}{c}\text { Pregabalin } \\
\text { Rauck et al., } 2013\end{array}$ & 0.225 & -0.060 & 0.511 & $P>0.05$ \\
\hline $\begin{array}{l}\text { Pregabalin } 150 \mathrm{mg} / \text { day } \\
\text { Richter et al., } 2005\end{array}$ & -0.407 & -0.744 & -0.070 & $P<0.05$ \\
\hline $\begin{array}{c}\text { Pregabalin } 600 \text { mg/day } \\
\text { Richter et al., } 2005\end{array}$ & -0.607 & -0.980 & -0.235 & $P<0.05$ \\
\hline $\begin{array}{l}\text { Duloxetine } 20 \mathrm{mg} / \mathrm{day} \\
\text { Goldstein et al., } 2005\end{array}$ & -1.622 & -1.650 & -1.594 & $P<0.05$ \\
\hline $\begin{array}{c}\text { Topiramate } \\
\text { Donofrio et al., } 2005\end{array}$ & -0.271 & -0.650 & 0.109 & $P>0.05$ \\
\hline $\begin{array}{c}\text { Tapentadol } \\
\text { Niesters et al., } 2014 \\
\end{array}$ & -1.333 & -1.594 & -1.072 & $P<0.05$ \\
\hline Oral treatment & -0.266 & -0.357 & -0.175 & $P<0.05$ \\
\hline $\begin{array}{l}\text { Capsaicin } \\
\text { Kulkantrakorn et al., } 2013\end{array}$ & -0.221 & -1.082 & 0.639 & $P>0.05$ \\
\hline $\begin{array}{c}\text { Clonidine } \\
\text { Campbell et al., } 2012\end{array}$ & -0.242 & -0.543 & -0.058 & $P<0.05$ \\
\hline Topical therapy & -0.238 & -0.524 & 0.047 & $P>0.05$ \\
\hline
\end{tabular}
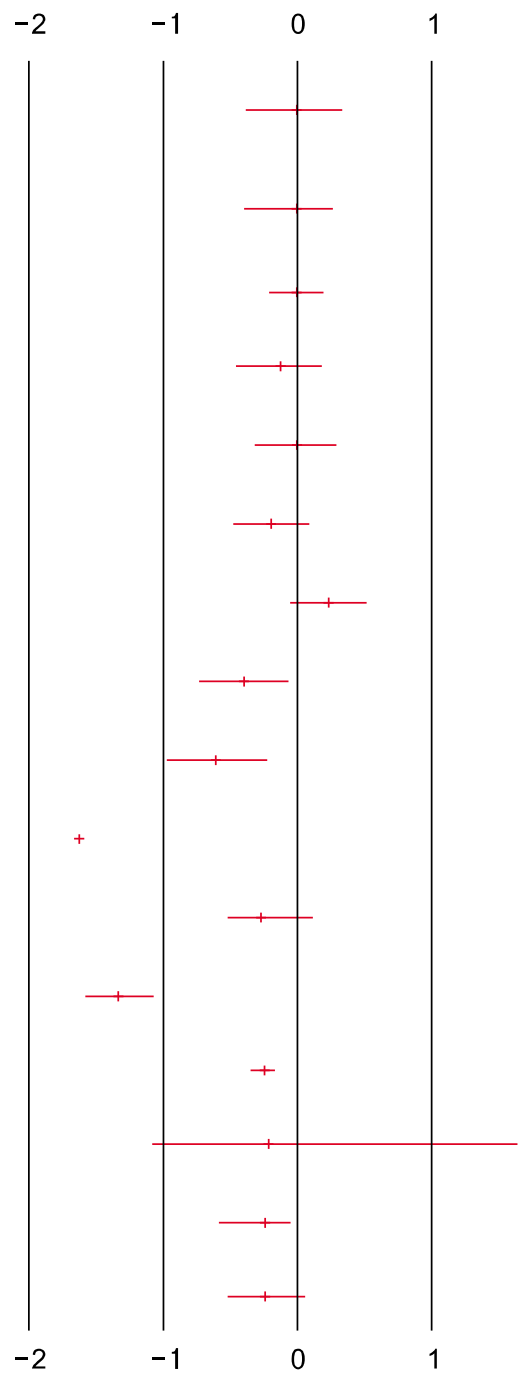

Fig. 4. Forest plot of meta-analytic results.

$\mathrm{mg} /$ day, since the rest of the doses did not have statistical viability) had a larger effect size regarding the assessment of the final pain of the patients.

These treatments are present in different clinical practice guidelines and recommendations for neuropathic pain, of which the most cited in the literature are those of the American Academy of Neurology (AAN) [7], the National Institute for Health and Care Excellence (NICE) [22], the European Federation of Neurological Societies (EFNS) [4] and the Neuropathic Pain Special Interest Group of International Association for the Study of Pain (NEUPSIG) [23].

The present study shows a high efficiency for the treatments based on gabapentin, duloxetine and pre- gabalin, which is in line with the aforementioned guidelines, in which they are categorized as first-level drugs for the treatment of painful diabetic neuropathy. In the case of gabapentin, in spite of being a study without effect according to the meta-analysis performed, it can be asserted that the results are positive regarding pain relief in the patients studied, especially at doses of 3600 $\mathrm{mg} /$ day.

Two other studies with positive results are those that tackled pain using tapentadol and clonidine. In the case of tapentadol, the results of the present study confirm that it is a useful drug for the treatment of painful diabetic neuropathy; however, the recommendations of the guidelines of the ENS and the NEUPSIG indicate that its use 
is better prescribed for painful processes in acute stages and short periods.

Of the rest of the oral or topical pharmacological therapies, it is worth mentioning that, although they were studies that did not obtain satisfactory results according to the meta-analysis conducted, they did show benefits related to pain relief.

A special case is that of physical therapies, which do not show satisfactory results, and are not valued or described in the recommendation guides, or they are not even recommended by the AAN [7].

The authors found as a limitation the absence of reply from the authors of different articles when contacting them to request more statistical data that would allow them to be included in the meta-analysis.

In conclusion, this meta-analysis indicates the effectiveness of the treatments based on duloxetine, gabapentin and pregabalin. Other drugs, such as tapentadol and topical clonidine, also obtained good results, although the use of the former may be limited to more specific situations. The physical therapies analyzed did not show any type of benefit for diabetic patients with neuropathic pain.

The present study followed a very strict methodology in the analysis and selection of clinical trials. Thereby, despite the fact that it was not possible to include a large number of studies, the results provided can help increase the knowledge about the treatment of painful diabetic neuropathy and the development of clinical practice guidelines for healthcare professionals.

\section{ACKNOWLEDGEMENTS}

We thank Antonia Sáez for her contribution as an external collaborator. SVP, PVM and MRB performed the search of literatura and selected the studies. SVP extracted data and entered the data into Revman. SVP, JMCL, and MPC wrote the manuscript. All authors discussed the results and commented on the manuscript.

\section{REFERENCES}

1. Ogurtsova K, da Rocha Fernandes JD, Huang Y, Linnenkamp U, Guariguata L, Cho NH, et al. IDF diabetes atlas: global estimates for the prevalence of diabetes for 2015 and 2040. Diabetes Res Clin Pract 2017; 128: 40-50.
2. Asociación Española de Enfermería Vascular y Heridas (AEEVH). Guía de práctica clínica: consenso sobre úlceras vasculares y pie diabético. Segunda edición. Seville, Asociación Española de Enfermería Vascular y Heridas. 2014. pp 1-90.

3. Boulton AJ, Vinik Al, Arezzo JC, Bril V, Feldman EL, Freeman $\mathrm{R}$, et al. Diabetic neuropathies: a statement by the American Diabetes Association. Diabetes Care 2005; 28: 956-62.

4. Attal N, Cruccu G, Baron R, Haanpää M, Hansson P, Jensen TS, et al. EFNS guidelines on the pharmacological treatment of neuropathic pain: 2010 revision. Eur J Neurol 2010; 17: 1113-23, e67-e88.

5. Stein C, Eibel B, Sbruzzi G, Lago PD, Plentz RD. Electrical stimulation and electromagnetic field use in patients with diabetic neuropathy: systematic review and meta-analysis. Braz J Phys Ther 2013; 17: 93-104.

6. Schreiber AK, Nones CF, Reis RC, Chichorro JG, Cunha JM. Diabetic neuropathic pain: physiopathology and treatment. World J Diabetes 2015; 6: 432-44.

7. Bril V, England J, Franklin GM, Backonja M, Cohen J, Del Toro D, et al. Evidence-based guideline: treatment of painful diabetic neuropathy: report of the American academy of neurology, the American association of neuromuscular and electrodiagnostic medicine, and the American academy of physical medicine and rehabilitation. Neurology 2011; 76 : 1758-65.

8. Park HJ, Moon DE. Pharmacologic management of chronic pain. Korean J Pain 2010; 23: 99-108.

9. Moher D, Liberati A, Tetzlaff J, Altman DG; PRISMA Group. Reprint---preferred reporting items for systematic reviews and meta-analyses: the PRISMA statement. Phys Ther 2009; 89: 873-80.

10. Jadad AR, Moore RA, Carroll D, Jenkinson C, Reynolds DJ, Gavaghan DJ, et al. Assessing the quality of reports of randomized clinical trials: is blinding necessary? Control Clin Trials 1996; 17: 1-12.

11. Higgins JP, Altman DG, Gøtzsche PC, Jüni $P$, Moher D, Oxman AD, et al. The Cochrane Collaboration's tool for assessing risk of bias in randomised trials. BMJ 2011; 343: d5928.

12. Higgins JP, Green S. Cochrane handbook for systematic reviews of interventions version 5.1.0 [updated March 2011] [Internet]. London, The Cochrane Collaboration. 2011 [cited 2018 March 3]. Available at http://handbook-5-1. cochrane.org/.

13. Goldstein DJ, Lu Y, Detke MJ, Lee TC, lyengar S. Duloxetine vs. placebo in patients with painful diabetic neuropathy. Pain 2005; 116: 109-18.

14. Niesters M, Proto PL, Aarts L, Sarton EY, Drewes AM, Dahan A. Tapentadol potentiates descending pain inhibition in chronic pain patients with diabetic polyneuropathy. $\mathrm{Br} J$ Anaesth 2014; 113: 148-56. 
15. Richter RW, Portenoy R, Sharma U, Lamoreaux L, Bockbrader H, Knapp LE. Relief of painful diabetic peripheral neuropathy with pregabalin: a randomized, placebocontrolled trial. J Pain 2005; 6: 253-60.

16. Campbell CM, Kipnes MS, Stouch BC, Brady KL, Kelly M, Schmidt WK, et al. Randomized control trial of topical clonidine for treatment of painful diabetic neuropathy. Pain 2012; 153: 1815-23.

17. Rauck R, Makumi CW, Schwartz S, Graff O, Meno-Tetang $\mathrm{G}$, Bell $\mathrm{CF}$, et al. A randomized, controlled trial of gabapentin enacarbil in subjects with neuropathic pain associated with diabetic peripheral neuropathy. Pain Pract 2013; 13: 485-96.

18. Weintraub MI, Herrmann DN, Smith AG, Backonja MM, Cole SP. Pulsed electromagnetic fields to reduce diabetic neuropathic pain and stimulate neuronal repair: a randomized controlled trial. Arch Phys Med Rehabil 2009; 90: 1102-9.

19. Weintraub MI, Wolfe Gl, Barohn RA, Cole SP, Parry GJ, Hayat $G$, et al. Static magnetic field therapy for symptomatic diabetic neuropathy: a randomized, double-blind, placebocontrolled trial. Arch Phys Med Rehabil 2003; 84: 736-46.

20. Donofrio PD, Raskin P, Rosenthal NR, Hewitt DJ, Jordan DM, Xiang J, et al. Safety and effectiveness of topiramate for the management of painful diabetic peripheral neuropathy in an open-label extension study. Clin Ther 2005; 27: 1420-31.

21. Kulkantrakorn K, Lorsuwansiri C, Meesawatsom P. $0.025 \%$ capsaicin gel for the treatment of painful diabetic neuropathy: a randomized, double-blind, crossover, placebo-controlled trial. Pain Pract 2013; 13: 497-503.

22. National Institute for Health and Care Excellence (NICE). Neuropathic pain in adults: the pharmacological management of neuropathic pain in adults in non-specialist settings. NICE clinical guideline. London, National Institute for Health and Care Excellence. 2013.

23. Finnerup NB, Attal N, Haroutounian S, McNicol E, Baron R, Dworkin RH, et al. Pharmacotherapy for neuropathic pain in adults: a systematic review and meta-analysis. Lancet Neurol 2015; 14: 162-73. 